\title{
Professores de Arquitetura Diante da Questão do Desenvolvimento Humano e da Inclusão Social das Pessoas Com Deficiência
}

\author{
Raquel Mazo* \& Lúcia Pereira Leite** \\ Universidade Estadual Paulista, Bauru, Brasil
}

\begin{abstract}
RESUMO
A Psicologia Histórico-cultural entende que o indivíduo se apropria da cultura e se desenvolve pelas interações sociais. $\mathrm{O}$ arquiteto atua indiretamente sobre o desenvolvimento humano, produzindo espaços que possibilitam variados níveis de interação entre os indivíduos. Para responder se os cursos de graduação brasileiros em Arquitetura formam profissionais que favoreçam a inclusão social das pessoas com deficiência, esta pesquisa investigou a concepção de professores de um curso público de Arquitetura sobre temas relacionados à problemática. Os relatos obtidos em entrevistas foram submetidos à análise de conteúdo categorial. Nos resultados, com exceção da concepção de Arquitetura, entendida como área do conhecimento que traz ganhos à vida humana, predominaram concepções pouco reflexivas e mais técnicas.
\end{abstract}

Palavras-chave: psicologia; acessibilidade; deficiência; ensino; arquitetura.

\section{ABSTRACT \\ Professors of Architecture on the Subject of Human Development and Social Inclusion of People With Disabilities}

Historical-Cultural Psychology believes that the people appropriate the culture and develop themselves by social interactions. The architect acts indirectly on human development by producing spaces that allow varying levels of interaction between individuals. To know if the Brazilian Architecture courses are graduating professionals who facilitate the social inclusion of people with disabilities, this research aimed to investigate the concepts of Architecture teachers of a public university about this theme. After the interviews, the reports obtained were submitted to the categorical-content analysis method. Technical concepts predominated over reflective ones, except for the architecture concept, classified as a knowledge area which brings gains to human life.

Keywords: psychology; accessibility; disability; teaching; architecture.

O desenvolvimento psíquico do homem depende de um processo de apropriação que se faz por intermédio de atividades mediadoras de sua ligação com a natureza, lhe conferindo o status de homem particular e social, determinando as suas possibilidades. Nas palavras de Leontiev (1978, p. 173) "para fazer os seus meios, as suas aptidões, o seu saberfazer, o homem deve entrar em relações com os outros homens e com a realidade humana material". Em termos mais específicos, para o autor, a apropriação da cultura é concebida como uma assimilação da experiência acumulada pela humanidade, no decorrer de sua história. É fun- damental para o desenvolvimento humano e ocorre por meio da linguagem. O processo de comunicação interacional coloca o ser humano em contato com os fenômenos do mundo. Em síntese, para desenvolver-se, o homem necessita do outro e, na relação eu-outro, significa-se e ressignifica a sua unicidade.

Consideremos que certos segmentos populacionais nem sempre conseguem estabelecer padrões interacionais diversos. Em outras palavras, que algumas pessoas são privadas em grande medida do contato e convívio social e, consequentemente, impedidas de se apropriar da cultura, na mesma proporção que a maior parte dos

* Endereço para correspondência: Raquel Mazo - raquelmazo@gmail.com.

** Endereço para correspondência: Lúcia Pereira Leite - lucialeite@fc.unesp.br. 
indivíduos. É o caso das pessoas com deficiência, pois em decorrência de limitações físicas e/ou sensoriais se veem privadas de acessar espaços socioculturais que deveriam ser disponíveis a todos, mantendo-se, então, à margem de algumas esferas sociais. Nesse contexto, a Arquitetura seria capaz de prover condições para que os espaços não se configurem como barreiras estruturais que impeçam que parte das pessoas se aproprie dos elementos da cultura, pois, em termos macroscópicos, a falta ou inadequação estrutural acaba por produzir atitudes pouco assertivas em relação aos excluídos. $\mathrm{O}$ fato de determinado segmento populacional deixar de acessar serviços e/ou instâncias de ordens diversas acaba por gerar distanciamento daqueles que os acessam; com isso, cria-se uma ideia de não pertencimento ou incompatibilidade.

No entanto, nos últimos anos, ações vêm sendo realizadas na tentativa de possibilitar a inclusão social das pessoas com deficiência, para que tenham acesso a todos os recursos da sociedade, uma vez que se entende que o meio é que deve se adaptar ou se ajustar às necessidades de segmentos populacionais distintos, para que se atenda aos princípios dos direitos humanos. Em outros termos, ao reconhecer a sua população sedimentada numa sociedade pluralista e multifacetada, constituída por um conjunto de segmentos populacionais diversos, e feito uma opção política formal pela universalização de direitos, que garanta e disponibilize oportunidades de acesso ao conhecimento historicamente produzido e sistematizado pela humanidade, o país assume o compromisso de investir em maneiras de fomentar a inclusão social (Leite, 2008).

O termo inclusão, segundo Aranha (2001), originou-se de um longo e importante processo histórico, de lutas de diferentes minorias, na busca de seus direitos. Atualmente, discute-se que a sociedade deveria prover serviços de avaliação e de capacitação da pessoa com deficiência e lhe caberia também se reorganizar, para garantir o acesso de todos a tudo o que a constitui e a caracteriza. Diante desse atual paradigma e amparado no pressuposto de que a pessoa com deficiência tem direito à convivência não segregada e acesso a todos os recursos que a sociedade dispõe aos demais cidadãos, cabe então à sociedade - representada pelas suas agências - prover suportes de diferentes tipos (social, físico, econômico, instrumental, entre outros), para favorecer a inclusão social de distintos grupos populacionais.
Fazendo uma alusão aos interesses deste texto, dar-se-á destaque às considerações sobre como a Arquitetura tem discutido questões referentes às adequações estruturais, enquanto formas de suporte para viabilizar a acessibilidade física da pessoa com deficiência a todo e qualquer espaço do qual tenha direito de usufruir.

O espaço construído, por ser planejado, não está estruturado ao acaso, e todas as articulações sociais a ele associadas exprimem um conteúdo ideológico, explícito ou não, que lhe imprime seus valores. Assim, o espaço construído não é neutro, reflete valores sociais dominantes e pode contribuir tanto para segregar como para integrar pessoas (Pinheiro, 2005). Esse tipo de reflexão nos remete à responsabilidade dos arquitetos e urbanistas, pois são profissionais que planejam e preveem a construção dos espaços, determinando de diferentes maneiras o destino de seus usuários.

Pinheiro (2005) defende que qualquer projeto arquitetônico deve priorizar o ser humano como o centro gerador, buscando a melhor condição de uso, função, segurança, bem-estar e acesso. Porém, muitas vezes, a Arquitetura concebe o usuário tendo como referência um "homem padrão", ideal, cujas medidas têm base em biótipos europeus ou americanos, que não correspondem a maior parte da população brasileira, afastando-se - e muito - do da pessoa com deficiência.

Como tentativa de reverter esse quadro, aparecem na Arquitetura, conceitos como "Desenho Universal", "acessibilidade", "mobilidade", entre outros, que propõem medidas para universalizar a utilização dos espaços (Kowaltowski \& Bernardi, 2005; Lanchoti, 2006; Pinheiro, 2005; Secretaria da Habitação e Desenvolvimento Urbano, 2002, 2003). Com isso, a construção passou a ser regida por leis e normas técnicas que prometem garantir o acesso indiscriminado aos espaços (Associação Brasileira de Normas Técnicas [ABNT], 2004, Decreto n. 5.296/2004; Lei n. 10.098/2000) e as diretrizes curriculares dos cursos de Arquitetura e Urbanismo foram reestruturadas, objetivando que os estudantes dessa área se tornem profissionais capacitados para construir espaços acessíveis (Parecer CNE/CES n. 112/2005; Resolução CNE/CES n. 6/2006).

No entanto, para Fernandino (2006), além de ser questionável a capacidade das agências de controle do cumprimento de tais normativas, as leis são baseadas em abstrações do uso ambiental. Desse modo, algu- 
mas edificações projetadas e construídas após a vigência da legislação, e em concordância com ela, não satisfazem ainda os níveis de competência ambiental das pessoas com deficiência, ou seja, deixam de possibilitar que essas pessoas se sintam seguras para usar o ambiente da mesma forma que as demais.

Para cumprir as regulamentações legais e exercer uma importante função, na sociedade, de agente promotor da inclusão social das pessoas com deficiência, o arquiteto precisa dominar alguns conhecimentos básicos. Primeiramente, espera-se que conheça a legislação e as normas técnicas de acessibilidade, sabendo aplicá-las ao planejamento e construção de edificações e cidades, de maneira a tornar esses espaços acessíveis a todos. Ainda, é importante que a formação em Arquitetura e Urbanismo esteja embasada em preceitos teórico-operacionais que possibilitem aos seus alunos atuarem como facilitadores do processo de inclusão social, o que incluiria, neste caso, conhecimento sobre desenvolvimento humano, inclusão social e deficiência, além do aporte técnico e normativo para elaboração de projetos arquitetônicos.

Atualmente, o ensino de Arquitetura se depara com a necessidade de responder a mudanças tecnológicas e econômicas, decorrentes de um mundo cada vez mais globalizado, tendo que preparar os alunos para o mercado de trabalho. Ao realizar a leitura de estudos de Garry Stevens no que se refere à atuação da arquitetura, Santos (2003) comenta que pode ser entendida como um campo que aloca instituições sociais, indivíduos, objetos e discursos numa empreita realizada por distintos participantes, com ênfase nos arquitetos - no que tange a capacidade de gerar efeito, já que seu discurso deve atender a clientes, agências financeiras e governamentais preocupadas tanto com o resultado das obras como com as normativas que a sustentam.

Ainda, ao realizar uma digressão histórica sobre o ensino da Arquitetura, Santos (2003) revela que as propostas curriculares se formatam em uma concepção homogênea e pouca crítica, que busca atender os interesses de uma lógica estritamente prática, com ações delimitadas, e que procuram atender fortemente às demandas politicoeconômicas. Em termos sintéticos, o autor destaca que as proposições curriculares perpetuam o ensino de [...] "um ofício em lugar de profissão, continuamos a reproduzir uma prática irrefletida, sem rigor de pesquisa" (Santos, 2003, p. 116). Com isso, o ensino de arquitetura valoriza mais a prá- tica retratada pela experiência individual de seus professores, do que investigações e estudos sistemáticos do seu campo de atuação.

Analisando as temáticas abordadas neste texto, percebe-se que reflexões metódicas sobre a função social do espaço construído raramente acompanham ou ganham destaque diante das demandas politicoeconômicas atuais. Entretanto, ao se entender que a diversidade da população é parte da natureza humana, fazse necessário ampliar atividades didáticas que provoquem reflexões críticas e busquem ofertar conceitos teórico-operacionais que rompam com modelos arquitetônicos baseados no ideal de homempadrão. Nessa direção, é competência das universidades, além de formar profissionais qualificados para o mercado de trabalho, propiciar que seus acadêmicos atuem como cidadãos atentos na promoção de ações materiais e/ou humanas que garantam a promoção dos princípios de igualdade (Duarte \& Cohen, 2003).

A concepção dos professores universitários é relevante, porque dá indícios sobre a forma como os conteúdos são transmitidos aos alunos durante a graduação, de sorte que, se a grade curricular não é capaz de transmitir de maneira sistematizada tais temáticas, os alunos podem ter contato por intermédio das discussões conduzidas pelos professores, em aulas de disciplinas não específicas. Nesse sentido, saber o que os professores pensam parece ser importante para entender quais conhecimentos são priorizados na formação acadêmica do futuro arquiteto, uma vez que o corpo docente tem autonomia para abordar determinados conteúdos ou posicionamentos acadêmicos, em detrimento de outros.

À luz de tais premissas, este estudo, que se constitui parte de uma de dissertação de mestrado, objetivou identificar os conceitos que o corpo docente de um curso de Arquitetura e Urbanismo apresenta sobre as seguintes temáticas: desenvolvimento humano, inclusão social, acessibilidade, deficiência e Arquitetura. No detalhamento, com a adoção desse objetivo, procurou-se identificar se esses professores compreendem as possibilidades de contribuição da Arquitetura às demandas sociais. Para os demais temas, foram investigados os valores atrelados à compreensão que os participantes apresentam sobre eles. 


\section{MÉTODO}

Participaram deste estudo, professores universitários, que constituíam o corpo docente de um curso de Arquitetura e Urbanismo, de uma universidade pública do Estado de São Paulo. O grupo era composto por dezesseis (16) professores, sendo nove (9) docentes do gênero feminino e sete (7) do gênero masculino, com idade variando entre 38 e 69 anos (idade média de 50 anos). O tempo com que os docentes estavam vinculados à universidade era de 15 anos, em média, sendo que metade dos participantes tinha mais de 20 anos de experiência em docência; dois deles com nível mestrado, nove com doutorado e cinco com pós-doutorado.

Antes de se proceder à coleta de dados, o projeto desta investigação foi submetido ao Comitê de Ética da instituição à qual esta pesquisa esteve vinculada e, somente após a sua aprovação, que consta no processo $n^{\circ} 252 / 46 / 01 / 09$, é que se deu início aos contatos com os participantes.

Quando da consulta do interesse em participar da pesquisa, os professores assinaram um Termo de Consentimento Livre e Esclarecido (TCLE), embasado nos preceitos da Resolução 196/96 do Conselho Nacional de Saúde, que dispõe sobre pesquisas envolvendo seres humanos. Os participantes também preencheram uma ficha de caracterização, na qual informavam dados pessoais (ano de nascimento e gênero) e dados profissionais (ano de formação, curso de graduação, níveis de pós-graduação e temas pesquisados, tipo e tempo de vinculação com a universidade, experiência em docência e área atual de pesquisa).

Para a coleta de dados, foi realizada entrevista individual com cada participante, momento em que foi aplicado um roteiro, composto de 26 questões, incluindo perguntas que objetivaram apenas o estabelecimento de rapport entre os entrevistados e a pesquisadora. As 20 perguntas de interesse para a pesquisa eram de livre interpretação, divididas em cinco grupos, sendo que cada grupo buscava apreender a concepção dos participantes sobre determinadas temáticas. A disposição das perguntas foi estratégica, para que os participantes não enviesassem suas respostas posteriores tendo conhecido as anteriores, pois a inteção de era que os participantes não soubessem que se tratava de uma pesquisa que relacionava o conceito de Arquitetura à problemática da inclusão social e desenvolvimento das pessoas com deficiência, através da acessibilidade. Por isso, o roteiro contou com a se- guinte ordenação das temáticas: Arquitetura, desenvolvimento humano, inclusão social, deficiência e acessibilidade.

Sobre os dados obtidos com as entrevistas com os professores, optou-se por utilizar o método de análise de conteúdo descrito por Bardin (1991). A análise de conteúdo é um conjunto de técnicas de análise de comunicações à luz de procedimentos sistemáticos e objetivos de descrição do conteúdo das mensagens. Esses procedimentos, segundo a autora, visam a obter indicadores (quantitativos ou não) que permitam a inferência de conhecimentos concernentes às mensagens que, nesse caso, foram produzidas por meio das perguntas realizadas, por meio de entrevistas.

Bardin (1991) apresenta diversas técnicas de análise de conteúdo. Entre elas, a análise de conteúdo categorial (ou temática), que é a técnica mais conhecida e utilizada e que foi empregada nesta pesquisa. A análise temática é transversal, quer dizer, recorta o conjunto das entrevistas, através de uma grelha de categorias, sendo contada a frequência dos temas extraídos do conjunto do discurso. Na análise em questão, foi contado o número de participantes que citou cada categoria.

\section{RESULTADOS}

Em relação ao tema Arquitetura, sobre o qual procurou-se apreender como os participantes compreendem sua área de conhecimento, sete categorias foram encontradas. A categoria de maior ocorrência foi "Promove qualidade de vida" (a número AA), mencionada por 14 participantes, ao passo que a segunda foi a categoria "É uma intervenção planejada" $(\mathrm{AB})$, com relatos de 9 participantes. As demais categorias foram citadas por cinco a sete participantes, sendo elas: categoria $\mathrm{AC}$ (Contribui esteticamente), $\mathrm{AD}$ (Atende às aspirações humanas) e $\mathrm{AE}$ (Atende às necessidades sociais). As categorias AF (É produção artística) e AG (Abriga as atividades humanas) foram citadas, respectivamente, por 4 e 3 professores.

Sobre o tema "desenvolvimento humano", de maneira geral, a pergunta levou os participantes a associar desenvolvimento a sete fatores, presentes no decorrer da existência dos indivíduos. As categorias mais citadas foram BA (Família), citada por 8 participantes, seguida pela categoria BB (Educação), por 7 participantes, e a categoria BC (Necessidades primárias atendidas), por 6 participantes. As três categorias restantes foram citadas por menos de 5 professores; são 
elas as categorias BD (Ações e características pessoais), BE (Suporte financeiro) e BF (Trabalho).

O tema "inclusão social" deu origem a oito diferentes categorias. As perguntas feitas aos participantes sobre este tema almejavam investigar se os participantes correlacionam os temas com deficiência ou pessoa com deficiência, focalizando o objetivo da pesquisa. Cada uma das categorias representa, portanto, um fator de exclusão, quando promove a marginalização de determinados segmentos populacionais; ou de inclusão, quando se concretiza em ações capazes de reverter o processo de exclusão. A categoria CA (Condições socioeconômicas) foi a mais citada, por 11 participantes. Em seguida, a categoria CB (Acessibilidade espacial), por 8, a categoria CC (Preconceito), 7, e a categoria CD (Características pessoais subjetivas), mencionada por 6 participantes. As categorias CE (Respeito aos direitos humanos), CF (Faixa etária), CG (Espaços de interação social) e CH (Participação política) foram citadas por menos de 4 professores, mas não deixam de fazer parte da concepção do grupo, como um todo.

Sobre o tema "deficiência", para exame dos resultados, foram usadas categorias pré-estabelecidas, provenientes dos estudos de Oliveira (2002, 2004), que investigaram a representação social de deficiência, em professores de diferentes áreas da educação especial, por intermédio de entrevista, que continha questões destinadas a compreender o conceito de deficiência, as características dos alunos com os quais atuavam e quais seriam os alunos que se beneficiavam dos serviços de educação especial. As respostas dos participantes dessas investigações foram distribuídas em três categorias analíticas: (a) concepção individual, (b) concepção psicossocial e (c) concepção interacionista. As mesmas categorias foram tomadas como referência, para a análise de conteúdo das respostas dos professores de Arquitetura, de nosso estudo.

Oliveira $(2002,2004)$ explica a concepção individual como aquela em que a deficiência está centrada no indivíduo, tomando, como referência, um desvio de padrão de normalidade, causado por falhas ou limitações que provoquem mau funcionamento em aspectos específicos da vida da pessoa com deficiência. A autora entende a concepção psicossocial como uma interpretação de que o mau funcionamento é decorrente de fatores sociais, emocionais ou educacionais, e não somente orgânicos, mas que também recaem sobre o indivíduo. Já a concepção interacionista se refere a uma maneira de ver a deficiência na relação estabelecida com a audiência, ou seja, é a interação com o outro que fará com que exista, ou não, a deficiência.

Em nossa pesquisa, ainda sobre o tema "deficiência", a categoria DA (Concepção individual) foi citada por 10 professores, seguida pela reposta de 4 deles na categoria DB (Concepção interacionista), e pela categoria DC (Concepção psicossocial), apenas 2 dos participantes.

Sobre o tema "acessibilidade", foram encontradas cinco categorias. As categorias EA (Definição técnica) e EB (Universalidade) foram citadas por 11 professores e, na sequência, as categorias EC (Inclusão social) e ED (Aspectos psicológicos), citadas por 6 professores. A categoria EE (Respeito a um direito humano) foi mencionada por 4 docentes, e a categoria EF (Limitações do conceito), por 3 deles.

\section{DISCUSSÃO}

Os resultados provenientes da análise dos relatos dos professores apontam dados interessantes. A começar pela concepção sobre a Arquitetura, grande ênfase foi dada aos ganhos que essa área do conhecimento tem na vida humana; mais especificamente, na qualidade de vida e no atendimento às necessidades humanas, inclusive as subjetivas.

Ao longo das entrevistas, os participantes se referiram ao termo Arquitetura, sob diferentes prismas: ora como atuação - arte, ciência ou profissão; ora como objeto - a própria obra arquitetônica.

A concepção dos professores revelou que o homem pode ser colocado em dois pontos distintos do processo de produção arquitetônica, de sorte que os resultados não esconderam uma oscilação desse posicionamento. Pensando no modo de se fazer Arquitetura, em seu início, esta é compreendida como uma ação criadora, enquanto o homem é enfatizado como aquele que produz a obra; e o arquiteto, o artista. Este é o caso das categorias AB (É intervenção planejada) e $\mathrm{AF}$ (É produção artística), as quais ressaltam o homem que faz Arquitetura, e não o homem que usa Arquitetura, como no seguinte relato de um dos participantes:

O arquiteto, ele sempre tem esse olhar (né?) de observar, isso é bom, isso é ruim, eu gosto... isso eu mudaria, mas as outras pessoas, não. (P6) 
Ao final desse mesmo processo, a Arquitetura é dada como contribuição para o homem, referindo-se àquele que faz uso, o cliente ou o usuário. É o caso das categorias AA (Promove qualidade de vida), AC (Contribui esteticamente), $\mathrm{AD}$ (Atende às aspirações humanas), AE (Atende às necessidades sociais) e AG (Abriga as atividades humanas). Todas as concepções de Arquitetura apresentadas nessas categorias corroboram definições da literatura que focalizam o homem como beneficiário da Arquitetura (Benevolo, 1999; Corona \& Lemos, 1998; Niemeyer, 2003; Okamoto, 1999). Esta concepção pode ser notada na resposta do participante $\mathrm{P} 4$, ao dizer:

A função do arquiteto é social [...] Ele tem conhecimentos específicos que vão ajudar a comunidade a se desenvolver, em vários aspectos: no aspecto psicológico, a coletividade [...] o potencial tecnológico de uma dada sociedade, pode ajudar até no desenvolvimento político. (P4)

Essa oscilação de concepções talvez represente a mesma instabilidade encontrada na literatura, deixando em contradição algo que deveria ser muito claro, ao menos para o arquiteto: o sentido da Arquitetura.

Além das sete categorias destacadas, foi observada uma característica comum aos relatos. De maneira geral, a concepção do grupo de professores é bastante positiva e não faz referência a nenhum tipo de limitação que, eventualmente, possa ser encontrado, na atuação profissional do arquiteto. Ao contrário, antes mesmo que lhes fosse perguntado sobre as contribuições da Arquitetura, a totalidade dos participantes já havia partido em defesa do conceito, atribuindo autoridade à Arquitetura e ao arquiteto, a saber: o poder de mudar, organizar e interferir no espaço e de abrigar e proteger o indivíduo.

Quanto aos resultados sobre a concepção de desenvolvimento humano, de todas as categorias citadas, as quais correspondem aos elementos necessários ao desenvolvimento de um indivíduo, nenhuma está associada a fatores sobre os quais a Arquitetura poderia intervir. Infere-se que, na concepção dos professores, o homem precisa da Arquitetura para o atendimento de suas necessidades, mas não para se desenvolver, o que parece incongruente, porque o desenvolvimento faz parte das demandas humanas - e das mais imprescindíveis.
Esta compreensão acerca do desenvolvimento humano pode ser percebida no conjunto de respostas, apresentadas na sequência, dadas à questão que solicitou a opinião dos professores sobre o que uma pessoa precisa para se desenvolver plenamente enquanto ser humano:

Ela precisa alimentação [...] saúde [...] (P2)

[...] você ter alimentos $[\ldots](\mathrm{P} 4)$

[...] pra poder ter condições de saúde, né?... que é prioritário, né?... saúde física, mental. Eu acho que são essas três coisas que são o tripé do ser humano: segurança, abrigo, você ter a saúde [...] (P8)

Possível explicação para tais respostas, talvez se ancorem numa concepção de desenvolvimento que se restringe ao desenvolvimento natural e/ou biológico, como a simples sobrevivência, distanciando-se de uma compreensão maior, que se ampare na origem sociocultural da subjetividade humana.

No que diz respeito ao tema "inclusão social", analisando-se o grupo de categorias como um todo, observa-se que, entre as oito categorias encontradas, as categorias CB (Acessibilidade espacial) e CG (Espaços de interação social) correspondem aos fatores de inclusão/exclusão, diretamente relacionados à Arquitetura, ou seja, se correlacionam a fatores sobre os quais a Arquitetura pode intervir, concretamente. Trata-se de um número reduzido de categorias que acrescentam a inclusão social ao escopo da Arquitetura e ainda metade dos participantes não citou nenhuma delas, o que demonstra que, na concepção do grupo, a inclusão social parece estar longe de ser considerada como parte das funções do arquiteto, corroborando com as considerações de Santos (2003). Ainda que a função da Arquitetura seja compreendida, tanto pelos próprios participantes, quanto pelas definições literárias (Corona \& Lemos, 1998; Ferreira, 2008), como a de promover contribuições à vida humana, o que, indiscutivelmente, envolve incluir as pessoas com deficiência, a análise demonstra a superficialidade ou o distanciamento com que esta temática é relatada pelos professores, no que tange à garantia de efetivar construções que possibilitem o alcance de todas as demandas sociais, incluindo as pessoas com deficiência ou mobilidade reduzida.

Os seguintes exemplos de resposta ilustram esta afirmação: 
Às vezes, o próprio negro (é excluído,) quando não tem acesso a um bom emprego. (P1)

Bom, normalmente eu acho que é... pessoas que passaram por penitenciárias, eu acho que são pessoas bastante excluídas [...] Os diferentes, né? (P8)

Os loucos são muitos os excluídos. (P10)

Mas nem sempre isso é assim; às vezes, aquele que vem de uma situação muito pior, é, tem mais esforço, ou tem mais garra do que aquele que tá sempre tratado a pão de ló e tá mal acostumado com isso. Então, eu acredito muito na perseverança das pessoas. [...] Eu acredito, antes de mais nada, nas pessoas e no esforço próprio. (P11)

Os resultados revelaram a necessidade de maior aprofundamento teoricoconceitual, por parte dos professores, pois a maioria das categorias foi formada por relatos reduzidos, os quais desconsideram as possibilidades de inclusão de segmentos populacionais segregados, através da Arquitetura. Mesmo tendo feito referência à acessibilidade, os relatos deixaram de explicar o que faz com que um espaço acessível seja também inclusivo, evidenciando que os participantes parecem não compreender, com clareza, o significado e a importância da inclusão social.

A respeito do tema "deficiência", na análise de frequência, tanto a categoria DA (Concepção individual) como a categoria DC (Concepção psicossocial) ressaltam o plano individual, em detrimento do social, totalizando 12 professores que compartilham de uma visão da deficiência que a focaliza apenas em âmbito individual. Com isso, a condição de deficiência e as problemáticas decorrentes passam a ser de responsabilidade daqueles que as possuem.

A pesquisa com professores de Arquitetura apresentou dados semelhantes aos de Oliveira (2002, 2004), visto que os resultados de sua investigação com professores de educação especial mostraram que $87 \%$ ainda colocam a deficiência no plano individual, sendo que pouco mais da metade faz alusão às condições individuais $(47,8 \%)$ e o restante às causas psicossociais $(39,2 \%)$.

Seria apropriado questionar as possíveis implicações que a concepção de deficiência teria sobre o trabalho do arquiteto, no que tange à pessoa com deficiência. No caso da Arquitetura, a concepção de deficiência terá efeito na relação que a sociedade estabelece com a pessoa com deficiência, uma vez que as concepções se refletem nas ações e, mais especificamente, neste caso, no ato de projetar e construir os espaços edificados, tornando-os acessíveis ou não. Com tais atitudes, altera-se também a própria deficiência.

Ao pensar em termos práticos, compreender a deficiência, à luz da concepção psicossocial, é entender que uma pessoa que se movimenta sobre cadeira de rodas tem uma deficiência, quando circula por calçadas sem guias rebaixadas, mas não tem a mesma deficiência, ao andar por espaços sem desníveis ou com rampas apropriadas, ou seja, ela continua tendo deficiência física, porém não está impossibilitada de acessar os espaços almejados.

Do ponto de vista interacionista, as limitações passam a existir dependentemente do julgamento da audiência, o que torna a deficiência possível de ser minimizada. Do contrário, por que motivo um arquiteto alteraria seus projetos, buscando soluções inovadoras para torná-los acessíveis, se concebe a deficiência como algo imutável, intrínseco ao indivíduo?

Em função disso, talvez, ampliam-se as prescrições normativas, como meio de obrigar o arquiteto a agir em concordância com um pensamento reflexivo - que pode ser diverso ao seu -, favorecendo a criação de soluções em prol da acessibilidade. Recorda--se que a acessibilidade deve ser compreendida como um direito e não como um favor, esperando-se que os profissionais da Arquitetura cumpram as normas, não pelo receio de sanções, mas sim por aceitarem a importância de se construir espaços sociais acessíveis a todos.

Entretanto, como visto nos dados expostos, mais da metade dos professores ainda apresenta uma concepção individual de deficiência, que a restringe apenas ao indivíduo que a possui. Tal concepção deixa de tomar o meio social como promotor de atitudes que podem minimizar ou não a inserção social da pessoa com deficiência e, consequentemente, o seu desenvolvimento. Numa alusão à especificidade dos participantes desta pesquisa, é preocupante que tais concepções sejam reforçadas, no cotidiano educacional, com os graduandos, deixando de promover reflexões críticas sobre como a sociedade e as ciências, em geral, têm entendido e lidado com a questão da deficiência e, por fim, viabilizar, ainda que em longo prazo, a inclusão social da pessoa com deficiência, por meio do trabalho do arquiteto.

$\mathrm{Na}$ análise do tema "deficiência", predominou, entre os professores, a concepção de deficiência locali- 
zada no indivíduo, desconsiderando a audiência social ou como o ambiente pode ser um agravador dessa condição, como se pode notar no relato:

A deficiência é quando você é incapaz de realizar alguma coisa, é incapaz de andar é incapaz de pensar, incapaz de ir e vir pra algum lugar, é uma incapacidade... Quando você diz assim 'o que é deficiência?'... 'Ah, eu sou deficiente disso' (sobre um aspecto), 'eu sou incapaz de fazer isso', não é? (P1)

Os dados corroboram a pesquisa de Mazo (2010), que demonstrou a carência de disciplinas e/ou conteúdos curriculares que abordem assuntos relacionados à inclusão social de pessoas com deficiência, nos curso de Arquitetura. Tal estudo analisou a grade curricular e o ementário de 40 cursos públicos de Arquitetura e Urbanismo existentes no país e como um dos achados destaca-se que, do montante analisado, somente nove (9) cursos apresentavam disciplina sobre acessibilidade, sendo que, em apenas um deles, era de natureza obrigatória e, nos demais, era ofertada como optativa. Sobre os demais temas investigados, desenvolvimento humano, inclusão social e deficiência, não foram encontradas disciplinas que fizessem referência ou que os abordassem de modo específico. Percebe-se, então, um descompasso entre o que é formalmente ensinado e o atendimento às demandas sociais, no caso, a necessidade da inclusão das pessoas com deficiência, em diversas instâncias sociais.

Contudo, encontraram-se algumas tentativas, as quais procuram, empiricamente, através de vivências, sensibilizar os alunos, aproximando-os à condição de deficientes, no intuito de motivar o interesse pela acessibilidade, enfatizando o lado negativo das dificuldades, causadas pelos impedimentos ao alcance e uso dos espaços construídos (Duarte \& Cohen, 2003; Lanchoti, 1998).

De maneira adicional, este estudo leva a acreditar que os alunos devam, também, participar diretamente do cotidiano das pessoas com deficiência, para analisar quais contribuições podem ofertar, para a melhoria do convívio nas situações de lazer, trabalho, educação, autocuidado. Com isso, poderão se apropriar das mais variadas formas de manifestação da cultura humana, acumulada e corporificada nas situações habituais.

A concepção de acessibilidade dos professores se aproximou muito de um entendimento técnico, ao contrário da concepção de Arquitetura, corroborando pesquisas desenvolvidas na área (Camisão, 2003;
Duarte \& Cohen, 2003; Fernandino, 2006; Kowaltowski \& Bernardi, 2005; Lanchoti, 2006; Pinheiro, 2005) e evidenciado, por exemplo, pela resposta:

Então, acessibilidade é a eliminação das barreiras arquitetônicas. (P6)

Em síntese, as categorias referentes às contribuições da acessibilidade à vida humana foram relatadas de maneira mais restrita e menos frequente do que aquelas voltadas aos aspectos técnicos ou mesmo que definem acessibilidade. A título de esclarecimento, recorda-se que as diretrizes curriculares nacionais (Resolução CNE/CES n. 6/2006) não estabelecem a obrigatoriedade de uma disciplina para o ensino de acessibilidade, nos cursos de arquitetura; cabe às próprias universidades optarem pela inserção da disciplina em seus currículos, seja em caráter obrigatório, ou como disciplina optativa.

Embora as definições técnicas de arquitetura façam referência a ela como produção para o homem, muitos arquitetos apresentam uma concepção de arquitetura voltada para a valorização da mesma como arte, destacando o homem, que está em um lado do processo, o produtor desta arte, o arquiteto. Tal ênfase se confirma pela presença, nas estantes das bibliotecas, de uma produção literária, em arquitetura, na qual predominam biografias e portfólios de arquitetos, nos quais textos e imagens apresentam vida e obras dos artistas. Felizmente, a pesquisa bibliográfica necessária ao desenvolvimento deste trabalho, se deparou com textos (Elali, 1997; Ittelson, Proshansky, Rivlin, \& Winkel, 2005; Moser, 2005; Ornstein, 2005; Romice, 2005) que contribuem em direcionar a arquitetura rumo a novos paradigmas, cujos holofotes se deslocam para iluminar aquele que deveria ser seu principal ator, que não é o arquiteto, mas o usuário. Para esses autores, a interdisciplinaridade entre psicologia e arquitetura é possível e importante, e, nos seus estudos, a psicologia ambiental é posicionada como ciência de interesse da Arquitetura, demonstrando, assim, interlocução entre as áreas.

Nesta pesquisa, para compreender o homem e, em particular, o seu desenvolvimento, recorreu-se aos constructos da psicologia, em especial, aos da psicologia historicocultural. Apoiado nesse referencial, acredita-se que, para o entendimento da acessibilidade, essas áreas podem ser complementares, pois os pressupostos psicológicos podem auxiliar numa compreensão mais ampla do ser humano, contextualizando-o 
culturalmente em determinado momento histórico e, ainda, contribuir nas discussões relacionadas à temática "deficiência", que ainda estão muito distante das propostas curriculares dos cursos de Arquitetura e Urbanismo, como verificado em pesquisa realizada por Mazo (2010), citada anteriormente.

Complementar a esse posicionamento, Duarte (2004) recorda a importância do ensino intencional, em qualquer nível acadêmico, e explica que as atividades sociais não podem se reproduzir se a humanidade, criada historicamente, não for reproduzida nos indivíduos. Até determinado momento histórico, os homens podiam se desenvolver pelo simples convívio social. Porém, a produção histórica de nossa humanidade atingiu tamanha complexidade que não é mais possível reproduzir essa humanidade em cada indivíduo, sem uma atividade direta e intencionalmente voltada para esse fim - que ocorre via educação formal. Soma-se a isso, o fato de que a sociedade capitalista passou a exigir conhecimentos e habilidades que não são mais adquiridos espontaneamente, de forma natural, tornando a educação, e ato educativo - dado por condições específicas de ensino, cada vez mais necessária. E tais condições não são diferentes no curso em análise.

Considera-se, então, que, além da ampliação do conceito de acessibilidade, o ensino de Arquitetura deve oferecer noções básicas de desenvolvimento, deficiência e inclusão social, ainda que não lide diretamente com as pessoas com deficiência. Retomando os apontamentos de Santos (2003), o currículo, embasado em posicionados críticos concatenados com aspectos científicos a serem amplamente difundidos em sala de aula, parece estar distante das proposições curriculares que subsidiam a formação acadêmica em Arquitetura.

Destarte, sabe-se dos limites deste estudo e, apoiada na informação da ampla proliferação de cursos de Arquitetura no país, face à crescente procura pela formação na área (Duarte \& Rheingantz, 2005), sugere-se a realização de novas pesquisas que extrapolem a investigação da área de projeto arquitetônico ou urbanístico e se debrucem a identificar e analisar condições específicas de propostas curriculares, que sustentem o ensino de Arquitetura numa perspectiva científica, comprometida com sua função humana e social.

\section{REFERÊNCIAS}

Aranha, M. S. F. (2001). Paradigmas da relação da sociedade com as pessoas com deficiência. Revista do Ministério Público do Trabalho, 11, 160-173.

Associação Brasileira de Normas Técnicas (2004). NBR 9050: Acessibilidade de pessoas portadoras de deficiência a edificações, espaço, mobiliário e equipamento urbano. Rio de Janeiro: Autor.

Bardin, L. (1991). Análise de conteúdo. Rio de Janeiro: Edições 70.

Benevolo, L. (1999). Introdução à arquitectura (M. M. Ribeiro, Trad.). Lisboa: Edições 70.

Camisão, V. (2003). Oficina de educação inclusiva no Brasil: Diagnóstico atual e desafios para o futuro. Rio de Janeiro: Banco Mundial. Retirado em 05 de setembro de 2009, de http://www.acessibilidade.net/at/kit2004/Programas\%20CD/A Ts/cnotinfor/Relatorio_Inclusiva/pdf/Acessibilidade_pt.pdf

Corona, L., \& Lemos, C. A. C. (1998). Dicionário da arquitetura brasileira. São Paulo: Companhia das Artes.

Decreto n. 5.296. (2004, 02 de dezembro). Regulamenta a Lei n. 10.436, de 24 de abril de 2002, que dispõe sobre a Língua Brasileira de Sinais - Libras, e o art. 18 da Lei no 10.098, de 19 de dezembro de 2000. Brasília, DF: Presidência da República. Retirado em 19 de março de 2008, de http://portal.mec.gov.br/ seesp/arquivos/pdf/decreto\%205296-2004.pdf

Duarte, N. (2004). Formação do indivíduo, consciência e alienação: O ser humano na psicologia de A. N. Leontiev. Cadernos CEDES, 24, 44-63.

Duarte, C. R. S., \& Cohen, R. (2003). O ensino da Arquitetura inclusiva como ferramenta para a melhoria da qualidade de vida para todos. Em F. Lara, \& S. Marques (Orgs.), Projetar: Desafios e conquistas da pesquisa e do ensino de projeto (pp.159-173). Rio de Janeiro: Virtual Científica.

Duarte, C. R. S., \& Rheingantz, P. A. (2005). Projetar 2005: Relato do segundo seminário nacional. Arquitextos, 6. Retirado em 26 de janeiro de 2010, de http://www.vitruvius.com.br/arqui textos/arq067/arq067_00.asp

Elali, G. V. M. A. (1997). Psicologia e Arquitetura: Em busca do locus interdisciplinar. Estudos de Psicologia, 2, 349-362.

Fernandino, S. F. (2006). Acessibilidade ambiental: Das disposições legais à inclusão espacial das pessoas com deficiência (Dissertação de mestrado). Universidade Federal do Rio de Janeiro.

Ferreira, A. B. H. (2008). Aurélio: O dicionário da língua portuguesa. Curitiba: Positivo.

Ittelson, W. H., Proshansky, H. M., Rivlin, L. G., \& Winkel, G. H. (2005). Homem ambiental. Série: Textos de Psicologia Ambiental, número 14 (J. Q. Pinheiro, Trad.). Brasília: UnB - Laboratório de Psicologia Ambiental.

Kowaltowski, D. C. C. K., \& Bernardi, N. (2005). Reflexões sobre a aplicação dos conceitos de desenho universal no processo de Arquitetura. Em Associação Nacional de Tecnologia do Ambiente Construído (Org.), Anais do Encontro Latino-americano sobre conforto no ambiente construído (pp. 155-163). Maceió. Retirado em 05 de setembro de 2009, de http://www.fec.uni camp.br/ doris/pt/artigos/con_html/pdf/Encac2005_desenho_u niversal.pdf 
Lanchoti, J. A. (1998). O ensino da eliminação de barreiras arquitetônicas nos cursos de arquitetura e urbanismo (Dissertação de mestrado). Universidade de São Paulo, São Carlos.

Lanchoti, J. A. (2006). Brasil Acessível - Programa Brasileiro de Acessibilidade Urbana - Caderno 2: Construindo a cidade acessivel. Brasília: Ministério das Cidades.

Lei n. 10.098 (2000, 19 de dezembro). Estabelece normas gerais e critérios básicos para a promoção da acessibilidade das pessoas portadoras de deficiência ou com mobilidade reduzida e dá outras providências. Brasília, DF: Ministério da Justiça. Retirado em 19 de fevereiro de 2008, de http://www.planalto.gov.br/ ccivil_03/leis/L10098.htm

Leite, L. P. (2008). Inclusão educacional e formação continuada: A busca por uma escola que atenda a todos os alunos. Em C. Meneguello (Org.), Diversidade (pp. 149-166). São Paulo: UNESP/Cultura Acadêmica.

Leontiev, A. (1978). O desenvolvimento do psiquismo (M. D. Duarte, Trad). Lisboa: Livros Horizonte.

Mazo, R. (2010). Ensino de Arquitetura e concepção de professores sobre acessibilidade, inclusão social, desenvolvimento humano e deficiência (Dissertação de mestrado). Universidade Estadual Paulista, Bauru.

Moser, G. (2005). A psicologia ambiental: Competência e contornos de uma disciplina. Comentários a partir das contribuições. Psicologia USP, 16, 279-294. Retirado em 05 de setembro de 2009, da base de dados SciELO.

Niemeyer, O. (2003). A cidade contemporânea. Em A. Xavier (Org.), Depoimento de uma geração: Arquitetura moderna brasileira (pp. 209-211). São Paulo: Cosac \& Naify.

Okamoto, J. (1999). Percepção ambiental e comportamento: Visão holística da percepção ambiental na arquitetura e na comunicação. São Paulo: IPSIS.

Oliveira, A. A. S. (2002). Representações sociais sobre educação especial e deficiência: $O$ ponto de vista de alunos deficientes $e$ professores especializados (Tese de doutorado). Universidade Estadual Paulista, Marília.
Oliveira, A. A. S. (2004). O conceito de deficiência em discussão: Representações sociais de professores especializados. Revista Brasileira de Educação Especial, 10, 59-74.

Ornstein, S. W. (2005). Arquitetura, urbanismo e psicologia ambiental: Uma reflexão sobre dilemas e possibilidades da atuação integrada. Psicologia USP, 16, 155-165. Retirado em 05 de setembro de 2009, da base de dados SciELO.

Parecer CNE/CES n. 112 (2005, 06 de abril). Diretrizes Curriculares Nacionais do Curso de Graduação em Arquitetura e Urbanismo. Brasília, DF: Ministério da Educação. Retirado em 19 de fevereiro de 2008, de http://portal.mec.gov.br/cne/arquivos/ pdf/pces0112_05.pdf

Pinheiro, H. L. (2005). Acessibilidade universal. Em O. Teske (Org.), Sociologia: Textos e contextos (pp. 345-352). Canoas: Ulbra.

Resolução CNE/CES n. 6 (2006, 02 de fevereiro). Institui as diretrizes curriculares nacionais do curso de graduação em Arquitetura e Urbanismo e dá outras providências. Brasília, DF: Ministério da Educação. Retirado em 19 de fevereiro de 2008, de http://portal.mec.gov.br/cne/arquivos/pdf/rces06_06.pdf

Romice, O. (2005). Conhecimento, interdisciplinaridade e psicologia ambiental. Psicologia USP, 16, 67-178. Retirado em 05 de setembro de 2009, da base de dados SciELO.

Santos, R. E. (2003). Currículo e qualidade de ensino. Cadernos de Arquitetura e Urbanismo, 10, 107-123.

Secretaria da Habitação e Desenvolvimento Urbano (2002). Guia de acessibilidade em edificações. São Paulo: Eder Santin.

Secretaria da Habitação e Desenvolvimento Urbano (2003). Guia para mobilidade acessível em vias públicas. São Paulo: Eder Santin.
Recebido: 03/01/2011

Última Revisão: 16/01/2012

Aceito: $30 / 02 / 2012$ 